\title{
Electrospun Scaffold of Collagen and Polycaprolactone Containing ZnO Quantum Dots for Skin Wound Regeneration
}

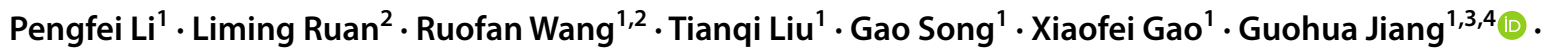 \\ Xiaoyan Liu ${ }^{5}$
}

Received: 17 March 2021 / Revised: 21 August 2021 / Accepted: 4 September 2021 / Published online: 22 November 2021

C Jilin University 2021

\begin{abstract}
Nanofibers (NFs) have been widely used in tissue engineering such as wound healing. In this work, the antibacterial $\mathrm{ZnO}$ quantum dots ( $\mathrm{ZnO} \mathrm{QDs})$ have been incorporated into the biocompatible poly ( $\varepsilon$-caprolactone)/collagen (PCL/Col) fibrous scaffolds for wound healing. The as-fabricated PCL-Col/ZnO fibrous scaffolds exhibited good swelling, antibacterial activity, and biodegradation behaviors, which were beneficial for the applications as a wound dressing. Moreover, the PCL-Col/ZnO fibrous scaffolds showed excellent cytocompatibility for promoting cell proliferation. The resultant PCL-Col/ZnO fibrous scaffolds containing vascular endothelial growth factor (VEGF) also exhibited promoted wound-healing effect through promoting expression of transforming growth factor- $\beta$ (TGF- $\beta$ ) and the vascular factor (CD31) in tissues in the early stages of wound healing. This new electrospun fibrous scaffolds with wound-healing promotion and antibacterial property should be convenient for treating wound healing.
\end{abstract}

Keywords Wound dressing $\cdot$ Issue engineering scaffold $\cdot$ Wound healing $\cdot$ Electrospun nanofibers

\section{Introduction}

Skin is the largest organ in the human body and provides us from external aggressions and pathogens $[1,2]$. However, skin injuries, including burns, diabetic ulcers, and other accidents, are considerable challenges in dermatology and skin care. Due to their vital functions as a physical, chemical, and bacterial barrier, the selection of skin woundhealing agents or dressings plays an important role in tissue

Pengfei Li and Liming Ruan have contributed equally to this work.

Guohua Jiang

ghjiang_cn@zstu.edu.cn

1 School of Materials Science and Engineering, Zhejiang SciTech University, Hangzhou 310018, China

2 Department of Dermatology, Beilun People's Hospital of Ningbo City, Ningbo 315800, China

3 Zhejiang-Mauritius Joint Research Center for Biomaterials and Tissue Engineering, Zhejiang Sci-Tech University, Hangzhou 310018, China

4 Institute of Smart Biomedical Materials, Zhejiang Sci-Tech University, Hangzhou 310018, China

5 Department of Dermatology, The 1st Affiliated Hospital of Zhejiang University, Hangzhou 310003, China restoration, prevention of dermal or systemic infections, and ultimately in the aesthetic outcome of wound healing [3]. During the past few decades, the development of electrospun fibrous scaffolds as wound dressings or matrices has been introduced as alternatives to traditional wound care products because of the simple electrospinning process, which does not require expensive or complex fabrication instruments, and the scaffolds porous structure similar to the human native extracellular matrix (ECM) [4, 5]. In addition, the electrospun nanofiber scaffolds have high porosity and high specific surface area, which are conducive to absorbing wound exudate and preventing the invasion of bacteria from the external environment [6]. The highly porous threedimensional (3D) structure of electrospun fibrous scaffolds can facilitate the exchange of cellular nutrients and create an ideal cellular micro-environment for wound healing [7-9]. Therefore, electrospun fibrous scaffolds have remarkable potential in both ECM-biomimetic structures and the ability to adsorb bioactive factors, and have thus emerged as essential applications in the field of skin wound repair [5, 10].

Skin wound healing is a complex process and involves several successive but overlapping phases, including hemostasis, inflammation, proliferation, and maturation (remodeling) [11-14]. Usually, electrospun fibrous scaffolds have been developed to cover wounds with the purpose to negate 
the occurrence of infections and avoid dehydration. However, this kind of passive dressings also can induce new lesions during replacement and are not effective against bacteria contaminations [15]. Therefore, it is urgent to develop the smart wound dressings, which should be able to support the human body to heal a wound as fast as possible with less scarring, patient pain, and discomfort [16].

In recent years, the use of biodegradable and biocompatible natural polymers, in combination with the electrospinning technique, has been widely investigated to obtain more and more efficient smart wound dressings [17-19]. For example, $\mathrm{Col}$ is a natural biological material and the major component of ECM. Collagen has been widely used in skin tissue engineering due to its excellent biocompatibility and weak antigenicity [20-22]. Although collagen can mimic native tissues best, and often lack sufficient mechanical strength to support a large number of cells, and collagen in particular is quickly consumed by enzymes in the body [23], thus hampering their efficient usage in large-scale wound treatments. This limitation might be overcome by combining collagen with other artificial polymers to form hybrid structures. PCL is a synthetic semi-crystalline linear polyester with good biocompatibility, biodegradable, and mechanical strength. And it is widely used in tissue engineering that approved by the U.S. Food and Drug Administration (FDA) as a biomedical material [24]. Although PCL exhibits significant mechanical strength and biocompatibility, it is inherently hydrophobic which negatively affects its biological properties such as cell adhesion and proliferation. Therefore, a combination of PCL with a natural hydrophilic polymer such as collagen is utilized as an ideal tissue engineering scaffold for wound healing [25]. Therefore, a combination of PCL with collagen can be utilized as an ideal scaffold for skin tissue regeneration.

In addition, any open skin wound is under the risk of microbial infection and provide potential invasion site for microbial growth and colonization, which result in trauma and delayed wound healing [26]. Therefore, immediate care of skin wounds with active wound dressings impregnated with antimicrobials is vital for prevention of microbial infection for acceleration of wound regeneration. Electrospun fibrous membranes are excellent soft scaffolds, delivering advanced therapeutic agents directly to the wound [27, 28]. Recently, the studies on incorporation of micro- and nanoparticles as additives into the wound dressing materials for the care of wounds are increasing. Especially, $\mathrm{ZnO}$ has widely used in biomedical engineering due to its good anti-inflammatory and antibacterial properties $[29,30]$. As previous reports [31-33], ZnO QDs as a cheap nanomaterial with low toxicity have shown great potential for application in wound healing. Because the $\mathrm{ZnO}$ QDs are decomposed completely at $\mathrm{pH} 5$ in aqueous solution, and the release of $\mathrm{Zn}^{2+}$ helps to promote wound repair by participating in the hair follicle regeneration, blood vessel formation, and wound-healing properties [34-37].

In the present work, the electrospun fibrous scaffolds have been fabricated by combination of PCL and Col. ZnO QDs and VEGF are further incorporated into the PCL/Col fibrous scaffolds for acceleration wound healing (Fig. 1). The objectives of the present work are: (1) to design and fabricate $\mathrm{ZnO}$ QDs-loaded PCL/Col electrospun fibrous scaffolds as wound dressings; (2) to evaluate structure, morphology, mechanical, swelling, and degradation, and antibacterial properties of as-prepared $\mathrm{ZnO}$ QDs-loaded PCL/Col electrospun fibrous scaffolds; (3) to determine the biological mechanism of wound healing.

\section{Experimental Section}

\subsection{Materials and Animals}

PCL $\left(M_{\mathrm{w}}=68-80 \mathrm{kDa}\right), 1,1,1,3,3,3$ - hexafluoro-2-propanol (HFIP, 99.5\%), magnesium acetate tetrahydrate $(99.0 \%)$, potassium hydroxide $(\mathrm{KOH}, 95 \%)$, n-hexane, $4 \%$ glutaraldehyde fixative were obtained from Aladdin Chemical Reagent Co., Ltd. (Shanghai, China). Dimethyl sulfoxide (DMSO) and Phosphate Buffer Solution (PBS) were supplied by Biyuntian Biotechnology Co., Ltd. (Shanghai, China). All chemical reagents are analytical grade. Collagen Type I was purchased from Solarbio Life Sciences. (Beijing, China). Fetal Bovine Serum (FBS) and Dulbecco's Modified Eagle Medium (DMEM) were obtained from ThermoFisher Scientific Co., Ltd. (Shanghai, China). Vascular Endothelial Growth Factor (VEGF) was supplied by PeproTech Co., Ltd. Escherichia Coli (E.coli) and Staphylococcus aureus (S. aureus) were purchased from Tongpai Biotechnology Co., Ltd. (Shanghai, China). Male Sprague-Dawley (SD) rats $(\sim$ weight of $200 \mathrm{~g})$ were provided by the Experimental Animal Center of Zhejiang Academy of Medical Sciences (Hangzhou, China). All the animal procedures were adopted and guided by the Animal Ethics Committee of Zhejiang Sci-Tech University (Acceptance Number: 2019-02-01).

\subsection{Fabrication of Electrospun Fibrous Scaffolds}

ZnO QDs were prepared by a sol-gel method and subsequently functionalized by (3-aminopropyl) triethoxysilane (APTEs) to form amino-functionalized $\mathrm{ZnO}$ QDs $\left(\mathrm{NH}_{2}-\mathrm{ZnO}\right.$ QDs, see Supplementary Material) [29, 30]. Then, different amounts of $\mathrm{NH}_{2}-\mathrm{ZnO}$ QDs $(0,0.25,0.5$ and $0.75 \% \mathrm{w} / \mathrm{v})$ were added to a PCL/Col (PCL: $\mathrm{Col}=2: 1,1: 1,1: 2$ and 1:3) solution in HFIP solution and then stirred slowly in a $20 \mathrm{~mL}$ vial about $24 \mathrm{~h}$ at room temperature. The high electrical voltage $(10-12 \mathrm{kV})$ was applied across a fixed distance of $12 \mathrm{~cm}$ between the needle tip and the collector. The feeding rate of 


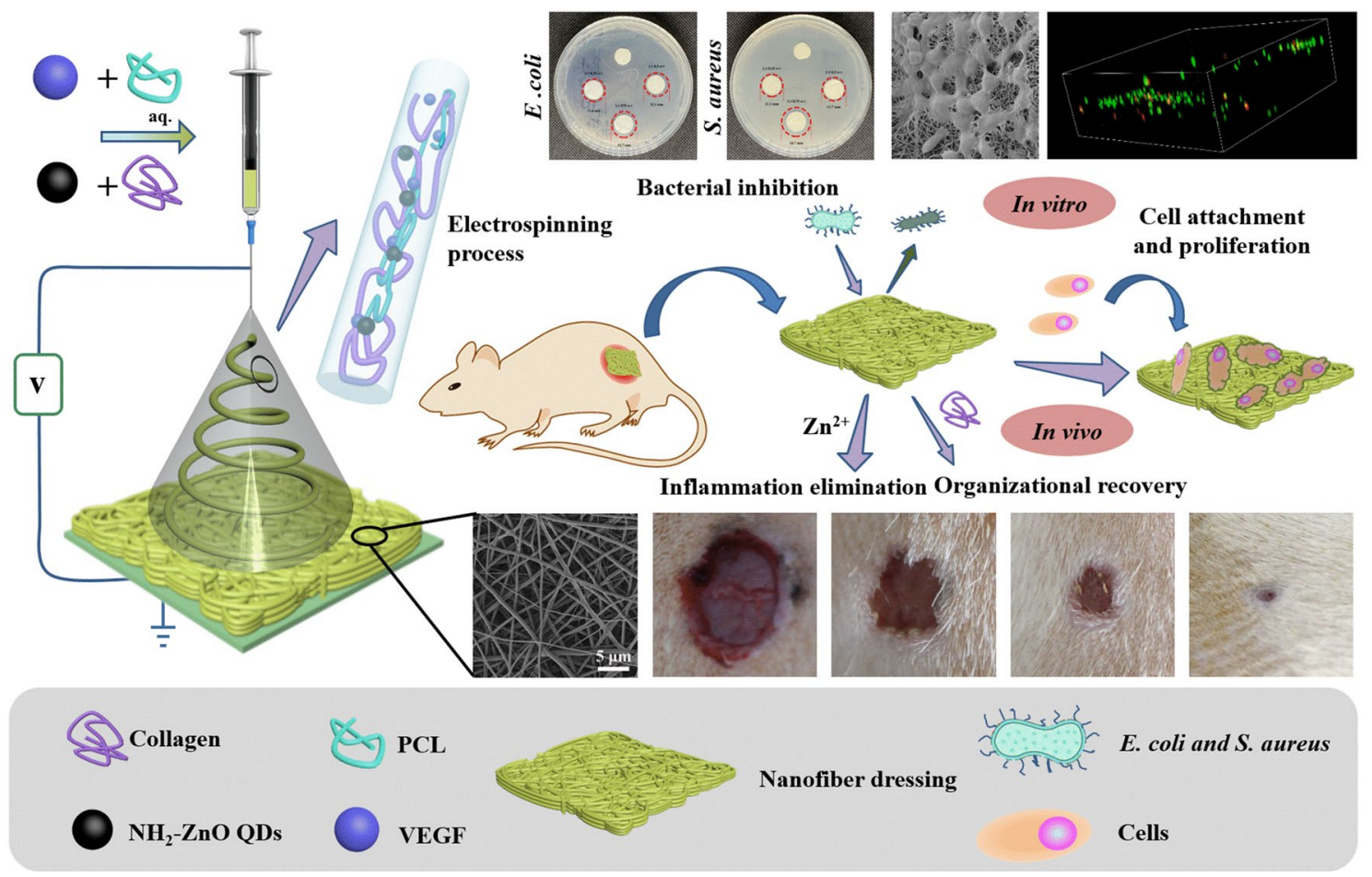

Fig. 1 Schematic illustration of electrospun PCL/Col scaffolds containing of ZnO QDs and VEGF for skin wound healing

the solutions was set at $1 \mathrm{~mL} \cdot \mathrm{h}^{-1}$. The electrospinning process was carried out under controlled conditions $\left(25 \pm 5^{\circ} \mathrm{C}\right.$ and $40 \pm 10 \% \mathrm{RH})$. All electrospun fibrous scaffolds were vacuum dried for $48 \mathrm{~h}$ to completely remove the solvent. Then, the fiber was soaked in $10 \mu \mathrm{g} \cdot \mathrm{ml}^{-1} \mathrm{VEGF}$ solution for $1 \mathrm{~h}$, and then dried for later use.

\subsection{Characterizations}

The scanning electron microscope (SEM) is used to observe the fibrous scaffolds microstructure. Water contact angle, mechanical property, Fourier transform infrared spectroscopy (FTIR spectra), swelling, porosity, and biodegradability tests were used to investigate the chemical and physical characterizations of composite films. The fiber diameter distribution of the different scaffolds was determined from the SEM micrographs using Image Analysis software (Image J, National Institutes of Health, Bethesda, USA). The details are available in Supplementary Material.

\subsection{Cell Cytotoxicity and Adhesion Tests}

To evaluate the cytotoxicity of the as-fabricated electrospun fibrous scaffolds, mouse fibroblast L929 cells and mouse embryonic fibroblast 3T3 cells were selected as model cells $[38,39]$. To evaluate the adhesion ability of the as-fabricated electrospun fibrous scaffolds, the cell morphology was tested by scanning and laser confocal (C2, Nikon, Japan). The detailed experimental process is provided in the Supplementary Material.

\subsection{Antibacterial Tests}

The electrospun fibrous scaffolds were cut into circles with a diameter of $10 \mathrm{~mm}$ plated on agar medium and treated with UV sterilization for 24 h. S. aureus and $E$. coli $\left(1 \times 10^{8} \mathrm{CFU} \cdot \mathrm{mL}^{-1}\right)$ were used to test the antibacterial ability of fibrous scaffolds [40, 41]. The zone of inhibition method was adopted to evaluate the bactericidal effect [42]. And the flat colony counting method was used to further evaluate the antibacterial strength after co-culture of fibrous scaffolds and $S$. aureus and E. coli at $37^{\circ} \mathrm{C}$ for $24 \mathrm{~h}$. Then, $100 \mu \mathrm{L}$ of the mixed cultured bacteria solution was evenly spread on the agar medium and cultured at $37{ }^{\circ} \mathrm{C}$ for $24 \mathrm{~h}$. After $24 \mathrm{~h}$, the number of colonies was marked to assess the antibacterial properties of the fibrous scaffolds.

\subsection{Wound Healing In Vivo}

The mouse full-thickness skin injury closure experiments were performed to assess the wound-healing properties of the as-fabricated electrospun fibrous scaffolds. First, male SD rats weighing about $200 \mathrm{~g}$ were anesthetized and shaved their back hair. Then, a full-thickness skin wound with a 
diameter of $10 \mathrm{~mm}$ was excised on the back of SD rats. Four different wound dressings (Group 1: gauze (control), Group 2: PCL-Col, Group 3: PCL-Col/Zn-0.75, and Group 4: PCL-Col/Zn-0.75 + VEGF) after UV sterilization were immediately applied to the wound surface. The wound area was recorded at different intervals time. Use Image $\mathbf{J}$ software to analysis calculate the wound rate, and then calculate wound-healing rate. The wound-healing ratio was calculated as $\left(A_{\mathrm{i}}-A_{\mathrm{u}}\right) / A_{\mathrm{i}} \times 100 \%$, where $A_{\mathrm{i}}$ is the initial area of the wound surface, and $A_{\mathrm{u}}$ is the area of the wound surface that did not recover.

\subsection{Histology and Immunohistochemistry}

The healed wound tissues were harvested and stained with hematoxylin and eosin (H\&E) and Masson's trichrome (Masson) for histology examination [43]. Then, immunohistochemistry analysis was performed to assess fibroblast differentiation and new blood vessels restore. The immunostaining for transforming growth factor- $\beta$ (TGF- $\beta$ ) and vascular factor (CD31) in wound tissue sections after different fibrous scaffolds treatments were performed at day 6 and 12 [44]. The details can be found in the Supporting Information.

\subsection{Statistical Analysis}

The statistical analysis was performed using the statistical software Origin Pro 2016 (OriginLab, Berkeley, CA, USA) and GraphPad Prism 8 (GraphaPad Software, San Diego, California, USA). The results above each data are compared and analyzed with the control group. All values were expressed as the mean \pm standard deviation (SD). Statistical comparisons were analyzed by a one-way ANOVA followed by Tukey test. A $p$ value less than 0.05 was considered statistical significance.

\section{Results and Discussion}

\subsection{Morphology of Scaffolds}

The pure ZnO QDs are synthesized by sol-gel method. Then, to improve the stability of $\mathrm{ZnO}$ QDs in aqueous solution, $\mathrm{ZnO}$ QDs are functionalized by APTEs to form $\mathrm{NH}_{2}-\mathrm{ZnO}$ QDs. Figure 2a, b shows their TEM and HRTEM images, showing a uniformly distribution after aminofunctionalized treatment. The size of most pure $\mathrm{ZnO}$ QDs is $9.1 \pm 0.5 \mathrm{~nm}$ (Fig. S1) and the space between two lattice fringes is $\sim 0.26 \mathrm{~nm}$ which corresponds to the (002) plane in $\mathrm{ZnO}$ QDs crystal. The XRD pattern of ZnO QDs presents the peaks at $2 \theta=31.89,34.40,36.34,47.59,56.48,62.78$, and 68.65 , corresponding to (100), (002), (101), (102), (110), (103), and (112) planes of hexagonal wurtzite structure of ZnO QDs (Fig. 2c) [45, 46]. Under UV light ( $\lambda=365 \mathrm{~nm}$ ), the obvious yellow fluorescence can be observed for the $\mathrm{ZnO}$ and $\mathrm{NH}_{2}-\mathrm{ZnO}$ QDs aqueous solution (Fig. 2d).

FTIR spectra of $\mathrm{ZnO}$ and $\mathrm{NH}_{2}-\mathrm{ZnO}$ QDs are recorded on a Fourier transformation infrared spectrometer (Bruker, Germany) and the results are shown in Fig. 2e. In the case of $\mathrm{ZnO}$ QDs, peaks at 458, 832, 1393, and $1509 \mathrm{~cm}^{-1}$ can be attributed to $\mathrm{Zn}-\mathrm{O}$ stretching [47]. After functionalized


Fig. 2 TEM and HR-TEM images of $\mathrm{ZnO}$ QDs (a) and $\mathrm{NH}_{2}-\mathrm{ZnO}$ QDs (b). X-ray diffraction images of ZnO QDs (c). Optical images of $\mathrm{ZnO}$ QDs and $\mathrm{NH}_{2}-\mathrm{ZnO}$ QDs under white light and UV irradia-
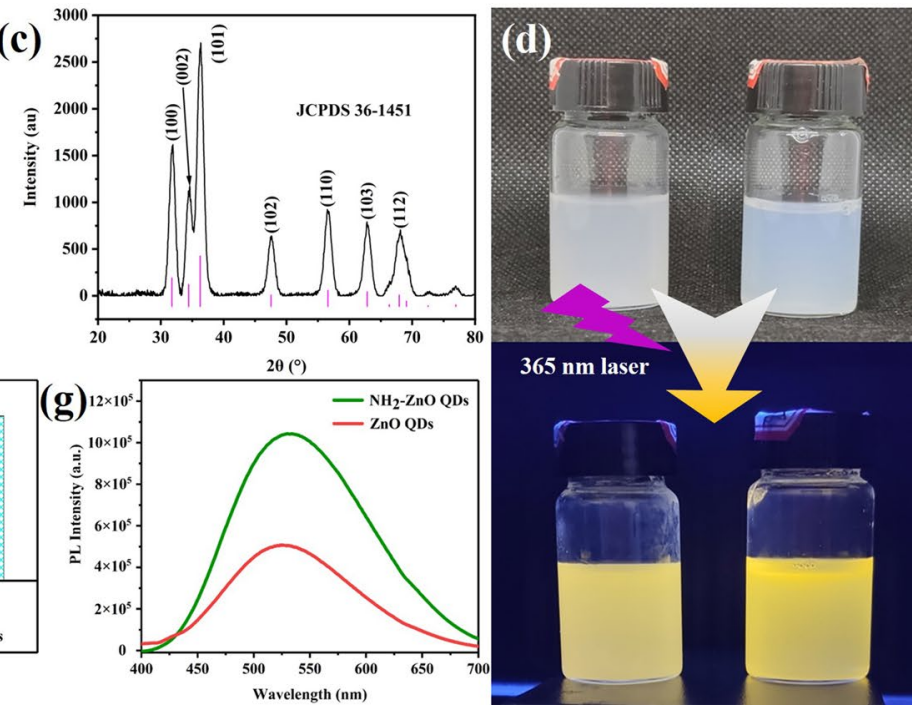

tion (d). FTIR spectra (e), surface zeta potential (f), and fluorescence spectra (g) of $\mathrm{ZnO}$ QDs and $\mathrm{NH}_{2}-\mathrm{ZnO}$ QDs 
by APTEs, the new band centered at $1650 \mathrm{~cm}^{-1}$ which corresponds to the bending vibration - $\mathrm{NH}$ - group indicates the presence of amino groups in $\mathrm{NH}_{2}-\mathrm{ZnO}$ QDs $[30,48]$. The absorption peak at $1002 \mathrm{~cm}^{-1}$ can be assigned to the stretching vibration of $\mathrm{Si}-\mathrm{O}$ band from APTEs. Therefore, the APTEs have been successfully modified on the surface of $\mathrm{ZnO}$ QDs [49]. Zeta potential measurements are conducted to confirm the surface electrokinetic potential of the synthesized $\mathrm{ZnO}$ QDs and $\mathrm{NH}_{2}-\mathrm{ZnO}$ QDs in aqueous solutions. The zeta potential of $\mathrm{ZnO}$ QDs is found to be $-3.85 \mathrm{mV}$. After functionalization, the positive zeta potential $(\sim 27.5 \mathrm{mV})$ is obtained for $\mathrm{NH}_{2}-\mathrm{ZnO}$ QDs (Fig. $\left.2 \mathrm{f}\right)$. The fluorescence excitation spectrum of the $\mathrm{ZnO}$ QDs, with an emission maximum at $365 \mathrm{~nm}$, exhibited a broad peak with a maximum at approximately $525 \mathrm{~nm}$. In fluorescence excitation spectrum of the $\mathrm{NH}_{2}-\mathrm{ZnO}$ QDs, suffers an enhancement along with the red shift (Fig. 2g).

Electrospun fibrous scaffolds are fabricated using mixed solutions of PCL $(10 \mathrm{w} / \mathrm{v} \%)$ and $\mathrm{Col}(10 \mathrm{w} / \mathrm{v} \%)$ in HFIP as raw materials under low relative humidity $(\mathrm{RH})(35 \%)$ and low temperature $\left(25^{\circ} \mathrm{C}\right)$ conditions [50] (Fig. 3a). Representative morphological images of fabricated electrospun fibrous scaffolds are shown in Fig. 3b. All scaffolds show randomly oriented uniform nanofibers with interconnected pores. Figure $3 \mathrm{c}-\mathrm{f}$ presents SEM images of electrospun PCL-Col fibrous scaffolds with different volume ratio (PCL/
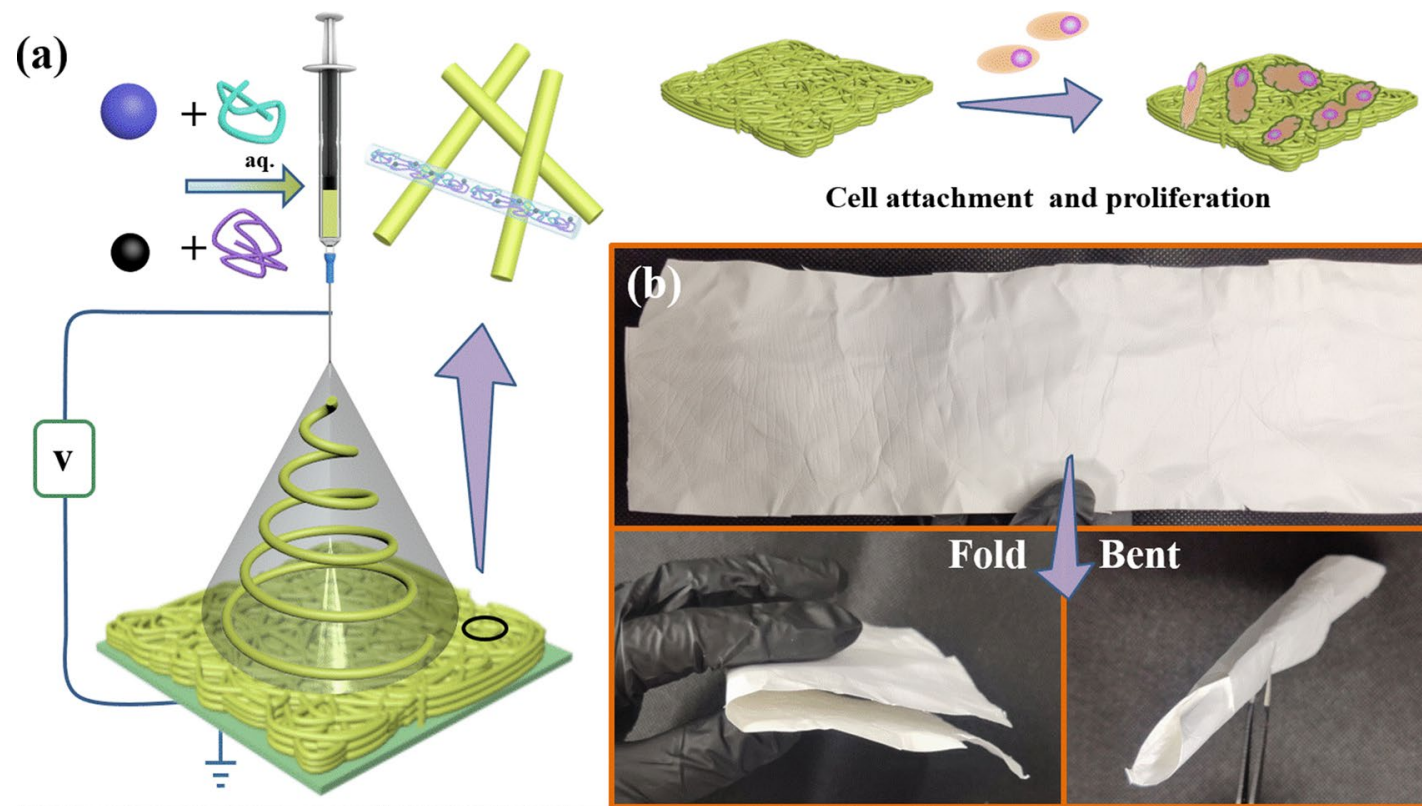

Cell attachment and proliferation


Fig. 3 Schematic illustration of the manufacturing process of electrospun PCL-Col fibrous scaffolds (a). Morphological images of fabricated electrospun fibrous scaffolds (b). SEM images and average

diameter histograms of electrospun PCL-Col fibrous scaffolds of with PCL/Col at 2:1 (c and $\mathbf{g}), 1: 1(\mathbf{d}$ and $\mathbf{h}), 1: 2(\mathbf{e}$ and $\mathbf{i})$, and 1:3 (f and $\mathbf{j})$ 
$\mathrm{Col}=2: 1,1: 1,1: 2$, and 1:3, respectively) of PCL and Col together with the corresponding size distribution graphs (Fig. $3 \mathrm{~g}-\mathrm{j}$ ). The fiber diameters of electrospun PCL-Col fibrous scaffolds are $360 \pm 80,530 \pm 110,360 \pm 80$, and $630 \pm 230 \mathrm{~nm}$ with volume ratio of PCL and Col at 2:1, 1:1, $1: 2$, and $1: 3$, respectively.

The surface hydrophilicity of nanofibrous scaffolds has a great influence on cell attachment and growth $[19,51]$. The hydrophobicity of the composite films is evaluated by the values of water contact angles. As shown in Fig. 4a, b, all electrospun PCL-Col fibrous scaffolds exhibit a good hydrophilicity with water contact angles ranged from 50 to $80^{\circ}$. And the water contact angles can be decreased to $20 \sim 55^{\circ}$ after the water drops placed on composite film for 90 s. It implies the electrospun PCL-Col fibrous scaffolds can absorb exudates during the wound-healing process [52, 53]. Among them, the electrospun PCL-Col fibrous scaffold prepared by $\mathrm{PCL} / \mathrm{COL}=1: 1$ shows the best hydrophilicity, which facilitates cell adhesion as well as cell-matrix interactions. Tensile properties of PCL-Col fibrous scaffolds are measured by universal testing machine (KSM-bx5450ST, Osaka Kato-tech, Japan). The stress-strain curves of PCLCol fibrous scaffolds are shown in Fig. 4c. Under a dry state, electrospun PCL-Col fibrous scaffolds with mass ratio of PCL and Col at 1:1 and 1:2 show higher force at break and elasticity, while the other scaffolds were characterized by significantly lower ones. The elongation at break electrospun PCL-Col fibrous scaffolds with mass ratio of PCL and Col at $1: 1$ and $1: 2$ are $~ 94.31 \%$ and $68.84 \%$, respectively. While, only $1.82 \%$ and $1.48 \%$ of elongation at break can be obtained for the scaffolds with mass ratio of PCL and Col at 2:1 and 3:1 (Fig. 4d). The tensile strength of scaffolds also exhibits the similar trend with $\sim 2.05$ and $2.01 \mathrm{MPa}$ for the first two samples and 1.13 and 0.43 MPa for the latter two noes (Fig. 4e). Therefore, the presence of PCL in the scaffolds seems to weaken the scaffold structure. Based on above results, the electrospun PCL-Col fibrous scaffold with PCL and Col at 1:1 has high tensile strength and good water-absorption properties which would be beneficial for wound dressing.

To enhance the antibacterial properties, $0.25,0.50$, or $0.75 \%$ of $\mathrm{NH}_{2}-\mathrm{ZnO}$ QDs relative to mass of PCL-Col are incorporated into electrospun PCL-Col fibrous scaffolds, denoted as PCL-Col/ZnO-0.25, PCL-Col/ZnO-0.5, and PCL-Col/ZnO-0.75, respectively. Compared with electrospun PCL-Col fibrous scaffold with smooth surface, the (a)
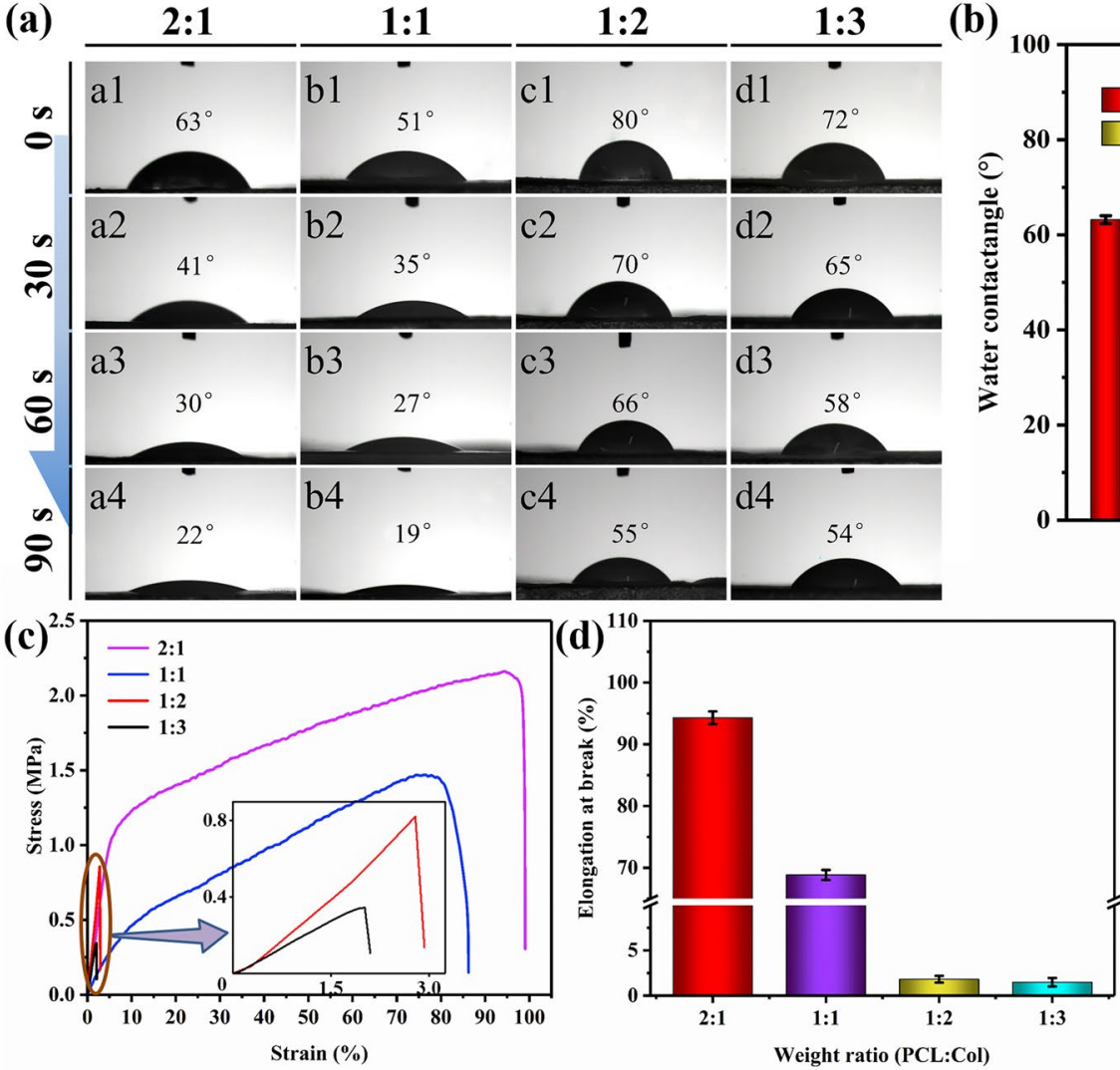

(b)

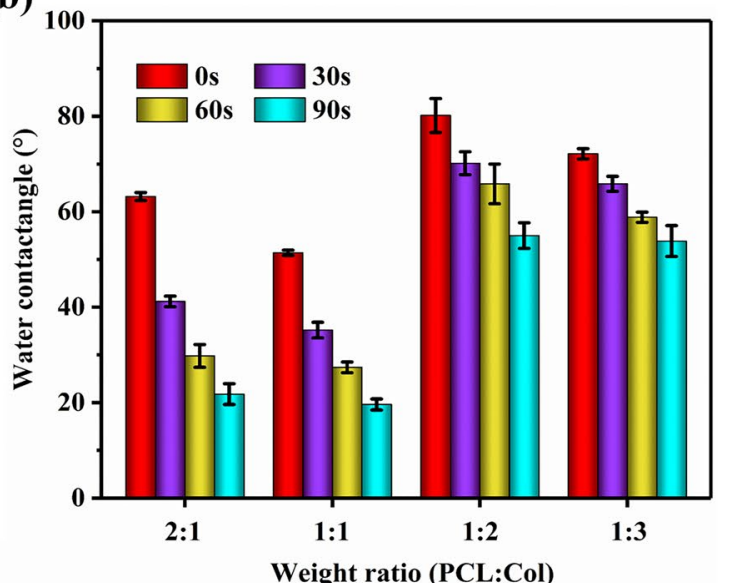

Fig. 4 WAC on various PCL/Col fibrous scaffolds at interval 0, 30, 60, and $90 \mathrm{~s}$ (a) and their quantitative analysis (b). Mechanical properties of stress-strain curves (c), elongation at break (d), and tensile strength (e) of the electrospun PCL/Col fibrous scaffolds 
electrospun PCL-Col/ZnO composite nanofibers show the well dispersion of $\mathrm{NH}_{2}-\mathrm{ZnO}$ QDs forming bead-string structure. And no significant aggregation of $\mathrm{NH}_{2}-\mathrm{ZnO}$ QDs is occurred (Fig. 5a-d). However, the diameter of the electrospun PCL-Col/ZnO composite nanofibers is lower than that of PCL-Col nanofibers (Fig. 5e-h). The presence of $\mathrm{ZnO}$ QDs in the fibrous scaffold was evaluated by the energy-dispersive spectrometer (EDS) elemental analysis. The results show that $\mathrm{O}, \mathrm{C}$, and $\mathrm{Zn}$ elements in mapping images are uniformly distributed on the fibrous scaffold (Fig. 5i). FTIR spectra of PCL, Col, $\mathrm{NH}_{2}-\mathrm{ZnO}$ QDs, and PCL-Col/ZnO0.75 also proved that $\mathrm{NH}_{2}-\mathrm{ZnO}$ QDs are successfully incorporated into electrospun PCL-Col fibrous scaffolds (Fig. S2).

\subsection{Physicochemical Evaluation of Fibrous Scaffolds}

The porosity of the wound dressing facilitates the absorption of wound tissue exudate and the maintenance of the extracellular environment at the wound [54]. As shown in Fig. 5j, the porosity of the as-prepared electrospun PCL-Col/ZnO fibrous scaffold is $\sim 82 \%$, which is higher than that of pure PCL (55.3\%) and PCL-Col composite nanofibers (75.5\%). It indicates that the incorporation of $\mathrm{NH}_{2}-\mathrm{ZnO}$ QDs facilitates the increasing the porosity of fibrous scaffolds. In addition, electrospun fibrous scaffolds should have good water absorption and moisture capability to prevent wound infection and accelerate the wound healing. The swelling rates of PCL$\mathrm{Col} / \mathrm{ZnO}$ fibrous scaffolds are significantly higher than that of pure PCL, and the swelling in the presence of $\mathrm{ZnO}$ QDs has a sharp increase in the first $25 \mathrm{~min}$ and shows higher water retention capacities in comparison with PCL-Col (Fig. 5k). These results indicate the good moisture capability of the PCL-Col/ZnO fibrous scaffolds. At the same time, the biodegradability of the wound dressing is also crucial. When the $\mathrm{pH}$ at 7.4 and 5.5, the biodegradation rates of the electrospun PCL-Col/ZnO-0.75 fibrous scaffolds can be reached to 48.98 and $48.37 \%$ after 15 days, respectively, which indicates that the PCL-Col/ZnO fibrous scaffold has good biodegradability (Fig. S3).

\subsection{Antibacterial and Cell Biocompatibility}

To determine the antibacterial efficiencies of PCL-Col/ $\mathrm{ZnO}$ fibrous scaffolds against $S$. aureus and $E$. coli, inhibiting the growth of bacteria is analyzed by a plate counting method. Figure $6 \mathrm{a}, \mathrm{b}$ shows the inhibiting the growth of $S$. aureus and $E$. coli with the concentration of PCL/Col, PCL$\mathrm{Col} / \mathrm{ZnO}-0.25$, PCL-Col/ZnO-0.5, and PCL-Col/ZnO-0.75 at $10 \mu \mathrm{g} \mathrm{mL}^{-1}$. After $24 \mathrm{~h}$ co-culture, the number of bacteria is decreased significantly for the PCL-Col/ZnO samples, and almost no S. aureus and E. coli can be found for PCL-Col/ $\mathrm{ZnO}-0.75$, indicating that the antibacterial properties can be improved by incorporation of $\mathrm{ZnO}$ QDs into fibrous scaffolds. Figure $6 \mathrm{c}$, d shows the quantitative statistical analysis results, showing the best antibacterial effect for PCL-Col/ $\mathrm{ZnO}-0.75$. This result also is confirmed by the inhibition zone tests (Fig. S4). The degree of antibacterial activity

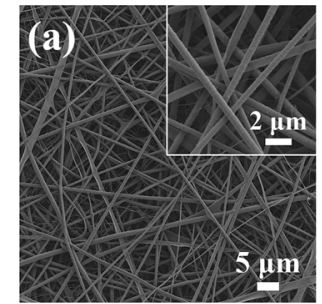

(e)

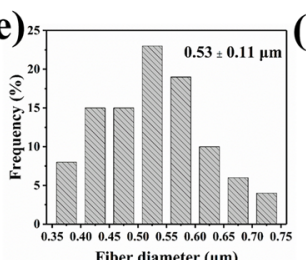

Fiber diameter $(\mu \mathrm{m})$
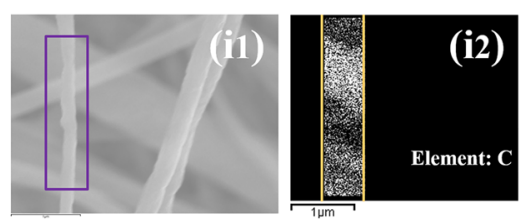
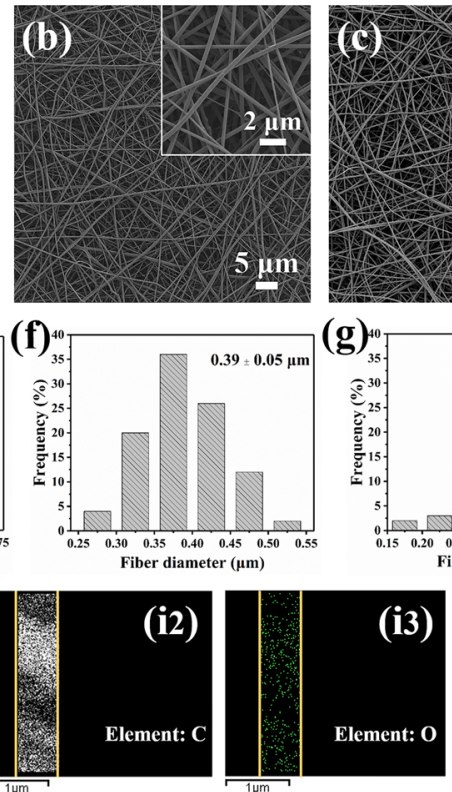
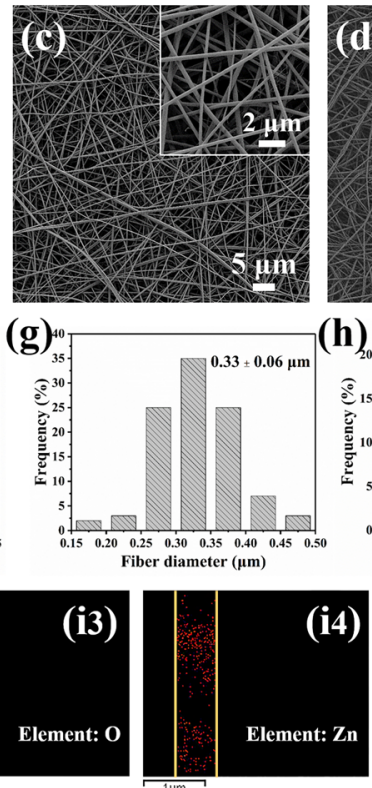
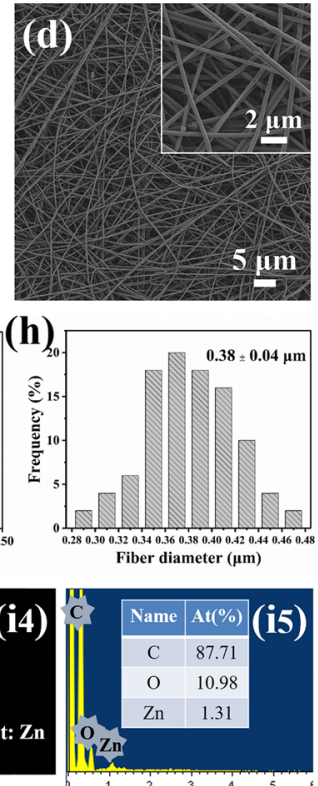
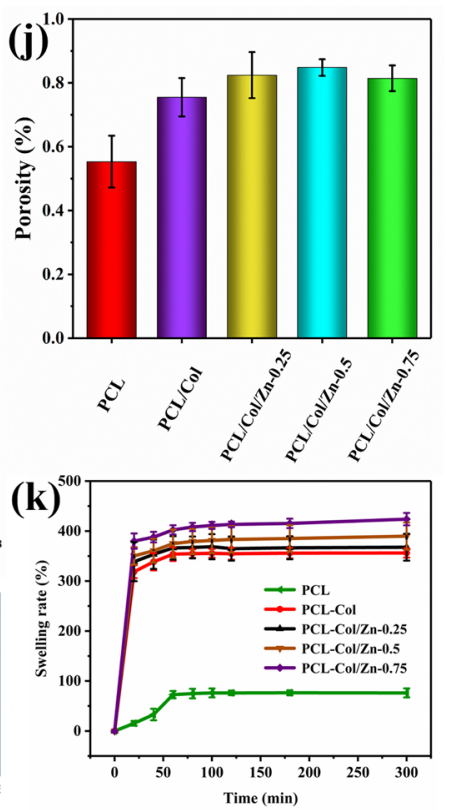

Fig. 5 SEM images and average diameter histograms of electrospun fibrous scaffolds of PCL-Col (1:1) (a and e), PCL-Col/ZnO-0.25 (b and f), PCL-Col/ZnO-0.5 (c and g), and PCL-Col/ZnO-0.75 (d and h). Mapping and EDS results of PCL-Col/ZnO-0.75 fibrous scaffolds (i). The porosity of fibrous scaffolds in this study (j). Swelling degree of nanofibers in PBS (pH: 7.4) (k) 



(h)

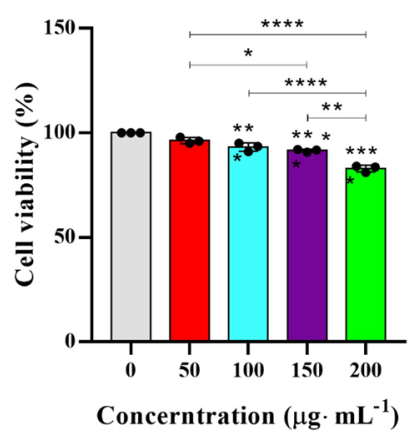

Fig. 6 In vivo fibrous scaffolds antimicrobial activities of PCL-Col, PCL-Col/ZnO-0.25, PCL-Col/ZnO-0.5, and PCL-Col/ZnO-0.75 against $E$. coli and $S$. aureus after co-cultivation $24 \mathrm{~h}(\mathbf{a}, \mathbf{b}, \mathbf{c}$ and d). CCK8 assay results of L929 (e) and 3T3 (f) cells after $24 \mathrm{~h}$ culture on fibrous scaffolds with concentration at $50 \mu \mathrm{g} / \mathrm{mL}$. Cytotoxicity of

L929 (g) and 3T3 (h) cells against PCL-Col/ZnO-0.75 fibrous scaffolds with different concentrations. SEM images of L929 adhesion and proliferation on the surface of PCL-Col/ZnO-0.75 fibrous scaffolds after 24 (i) and $48 \mathrm{~h} \mathrm{(j)}$

depends upon the amount of $\mathrm{ZnO}$ QDs in the fibrous scaffolds [55].

Cytotoxicity assay is done to estimate the cell viability of L929 and 3T3 cells lines with different substrate scaffolds. Figure 6e, f shows that PCL-Col and PCL-Col/ $\mathrm{ZnO}$ fibrous scaffolds have no significant negative impact on cell viability after $24 \mathrm{~h}$ culture in comparison with PCL. Higher amount of PCL-Col/ZnO-0.75 only causes a slight decline on cell viability, as shown in Fig. $6 \mathrm{~g}$, $\mathrm{h}$.

To evaluate the in vitro cell proliferation on fibrous scaffold, L929 cell is chosen to be co-cultured with PCL-Col/ $\mathrm{ZnO}-0.75$ fibrous scaffolds. Figure 6i, j shows the SEM images of L929 adhesion and proliferation on the surface of PCL-Col/ZnO-0.75 fibrous scaffold after culture for 24 and $48 \mathrm{~h}$. These is significant increases in the number of L929 cell over time. In addition, the morphology of L929 cells shows a clear preference spreading along the direction of nanofibers. 


\subsection{Wound Healing In Vivo}

To evaluate the ability of $\mathrm{ZnO}$ QDs incorporated fibrous scaffolds on the wound healing, a full-thickness skin wound $(10 \mathrm{~mm}$ in diameter) is established on the back of mice. The medical gauze-treated wounds, the wounds treated with PCL-Col, PCL-Col/ZnO-0.75, and PCL-Col/ ZnO-0.75 + VEGF fibrous scaffold are observed. On the day of implantation and each day after the implantation until the wound completely healed, photographs are taken and shown in Fig. 7a. The wound-healing rates are significantly different among all groups at each time point. On the 6th day, wound-healing rates are $\sim 29,53,63$, and $78 \%$ for gauze, PCL-Col, PCL-Col/ZnO-0.75, and PCL$\mathrm{Col} / \mathrm{ZnO}-0.75+$ VEGF groups, respectively. On the 12th day, it can also be observed, from the image, that the wound tissue restored almost completely in PCL-Col/ZnO$0.75+$ VEGF group and a very small portion of the wound remained unhealed in other groups. Wound contraction was also quantified in terms of percentage and the results are expressed in Fig. 7b. The PCL-Col/ZnO-0.75 + VEGF fibrous scaffold can significantly promote wound healing. On the day 4th, the percentage of wound area treated with PCL-Col/ZnO-0.75 + VEGF is $66 \%$, and it can be decreased to 22 and $3 \%$ after 6 and 12 day treatments. The wound closure rate also can be increased to $~ 95.4 \%$ in comparison with 92 and $88 \%$ for PCL-Col/ZnO-0.75 and PCL-Col groups, and significantly higher than that of the gauze group at $77 \%$ (Fig. $7 \mathrm{c}$ ).

\subsection{Histology and Immunohistochemistry Evaluation}

Histological studies are used to evaluate the efficiency of the treatments on the wound-healing process; based on the histological observations stained with H\&E shown in Fig. 8a. At day 6, many inflammatory cells (black arrow) and few neovascularization (red arrow) can be observed on the control group. However, fewer inflammatory cells can be founded in the PCL-Col/ZnO-0.75 and PCL-Col/ZnO$0.75+$ VEGF group due to the effective antibacterial ability of $\mathrm{ZnO}$ QDs in vivo. The quantitative analysis of the inflammatory cell number is presented in Fig. 8b. On the 6th day, the number of inflammatory cells can be decreased from 195 for gauze group to 118,102 and 75 for PCL-Col, PCL$\mathrm{Col} / \mathrm{ZnO}-0.75$, and PCL-Col/ZnO-0.75 + VEGF groups on $1 \mathrm{~mm}^{2}$ wound area (Fig. 8c). After 12 day treatment, the number of inflammatory cell can be further decreased to
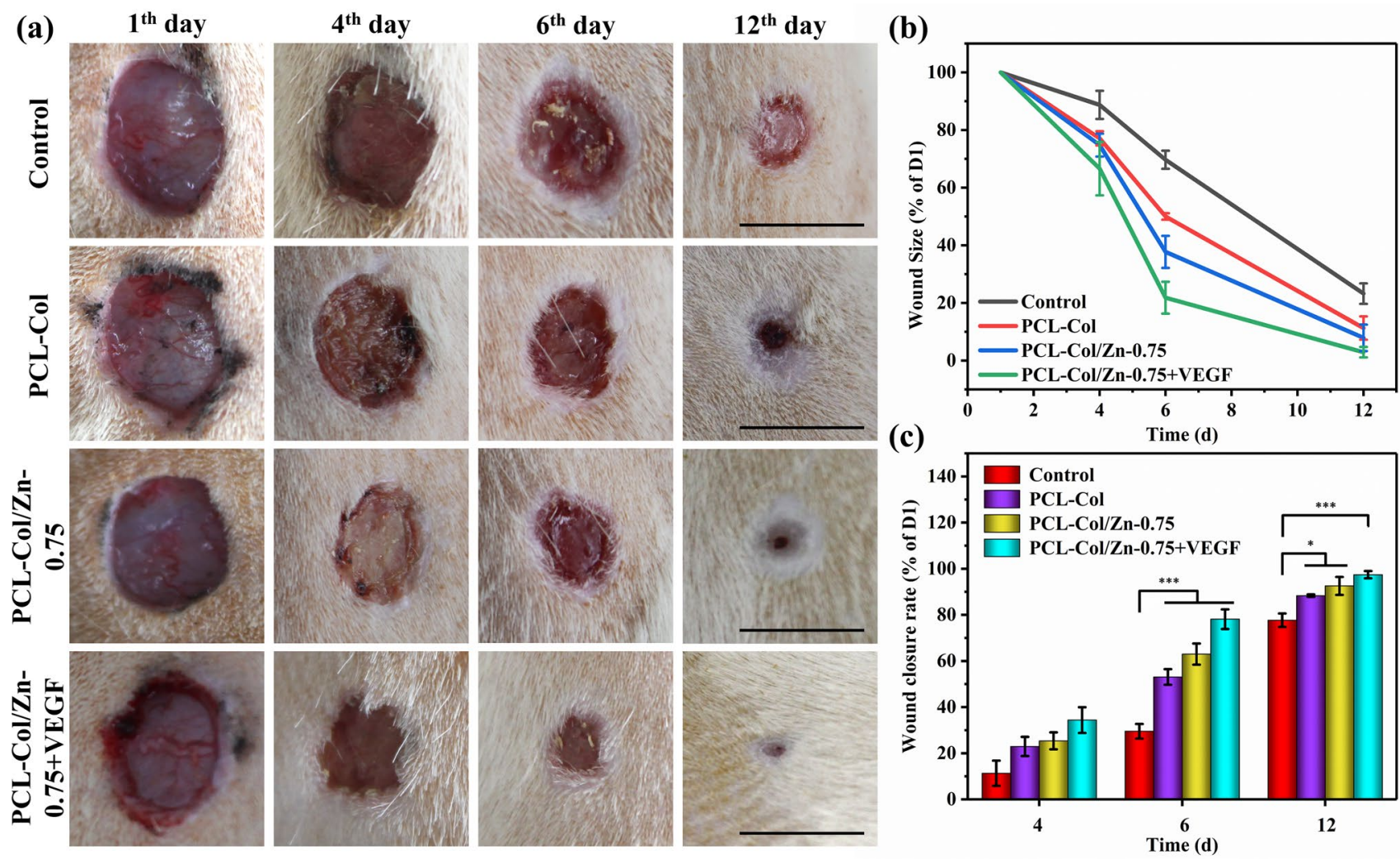

Fig. 7 Wound-healing effects of control, PCL-Col, PCL-Col/ZnO0.25, PCL-Col/ZnO-0.5, and PCL-Col/ZnO-0.75 fibrous scaffolds on the wound. Wound images after treated by different fibrous scaffolds

at days 1, 4, 6, and 12, scale bars: $1.0 \mathrm{~cm}(\mathbf{a})$. Wound size (b) and wound closure rate (c) treated with different fibrous scaffolds at days $1,4,6$, and 12 

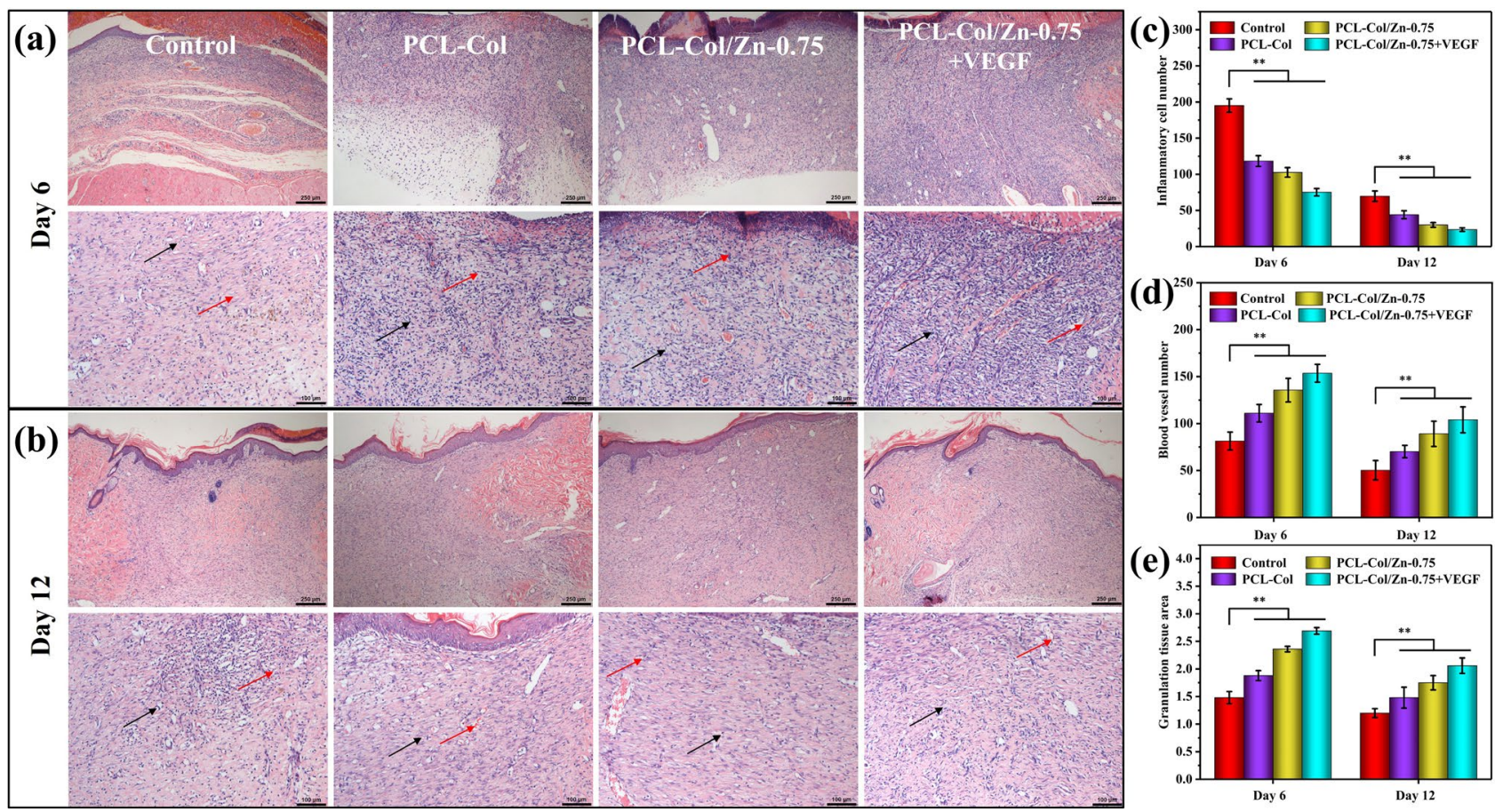

Fig. $8 \mathrm{H} \& \mathrm{E}$ stained images of wound tissue after treatments day 6 (a) and day 12 (b), scale bars: $100 \mu \mathrm{m}$. Corresponding quantitative analysis of the inflammatory cell number $(\mathbf{c})$, blood vessel number $(\mathbf{d})$, and granulation tissue area (e) at day 6 and 12

23. While, the number of new blood vessels and granulation tissue exhibits an opposite trend (Fig. 8d, e). The most of new blood vessels and granulation tissue can be formed in the PCL-Col/ZnO-0.75 + VEGF groups, which can establish a sufficient blood supply that provides a favorable microenvironment for epidermal and dermal cell migration and proliferation [56, 57].

To further investigate the mechanism of skin wound healing, the wound collagen deposition, inflammation condition, and angiogenesis are evaluated by Masson trichrome staining, TGF- $\beta 1$, and CD31 immunohistochemical staining. Figure 9a shows the results of Masson's trichrome staining to assess the collagen deposition in the wound site. A large number of collagen fibers and myofibrils are appeared in the PCL-Col/ZnO-0.75 + VEGF group. The quantitative analysis results are provided in Fig. $9 \mathrm{~b}$. The collagen area ratio in the PCL-Col/ZnO-0.75 + VEGF group can be increased to 29.1 after 6 days of treatment compared with PCL-Col/ $\mathrm{ZnO}-0.75$ at $25.8 \%$ and PCL-Col at $24.9 \%$. This indicates that the $\mathrm{ZnO}$ and VEGF can accelerate the production of collagen fibers to promote wound closure. On 12th day, the collagen index can be further increased to $39.8 \%$ for PCL$\mathrm{Col} / \mathrm{ZnO}-0.75+\mathrm{VEGF}$ group, showing the highest collagen content in all groups (Fig. 9b).

In addition, the immunohistochemistry assessment of transforming growth factor and vascular factor is performed. TGF- $\beta 1$ can promote the contraction of fibroblasts on the collagen matrix, thereby accelerating collagen deposition, wound healing, and re-epithelialization [58-60]. On the 6th day, the TGF- $\beta$ expression levels in the gauze, PCL-Col, PCL-Col/ZnO-0.75, and PCL-Col/ZnO$0.75+$ VEGF are $0.12 \pm 0.01,0.14 \pm 0.02,0.15 \pm 0.01$, and $0.17 \pm 0.02$, respectively. On the 12 th day, the expression levels of the same three groups are $0.10 \pm 0.01$, $0.11 \pm 0.02,0.12 \pm 0.02$, and $0.13 \pm 0.01$ (Fig. 9c, d). There is reduced TGF- $\beta$ expression after 12 day treatment in comparison with that in 6 day treatment. It indicates that PCL-Col/ZnO-0.75 + VEGF can promote the secretion of TGF- $\beta$ in the initial stage of wound healing, and decrease its expression in the final stage. CD31 is a marker of vascular endothelial cells which is one of the criteria for evaluation of wound tissue recovery [61-63]. After treatment for 6 days, the CD31 expression levels in the gauze, PCLCol, PCL-Col/ZnO-0.75, and PCL-Col/ZnO-0.75 + VEGF are $0.02 \pm 0.00,0.23 \pm 0.01,0.24 \pm 0.01$, and $0.25 \pm 0.02$, respectively. On the 12th day, the expression levels of the same three groups are $0.13 \pm 0.01,0.14 \pm 0.01,0.15 \pm 0.01$, and $0.16 \pm 0.02$ (Fig. 9e, f). These results show that the PCL-Col/ZnO-0.75 + VEGF stimulates expression of CD31 in the initial stage of wound healing, and decreases its expression in the final stage of wound healing as well. It also implies PCL-Col/ZnO-0.75 + VEGF can promote angiogenesis in the early stages of wound healing and should decrease it in the later stages. 

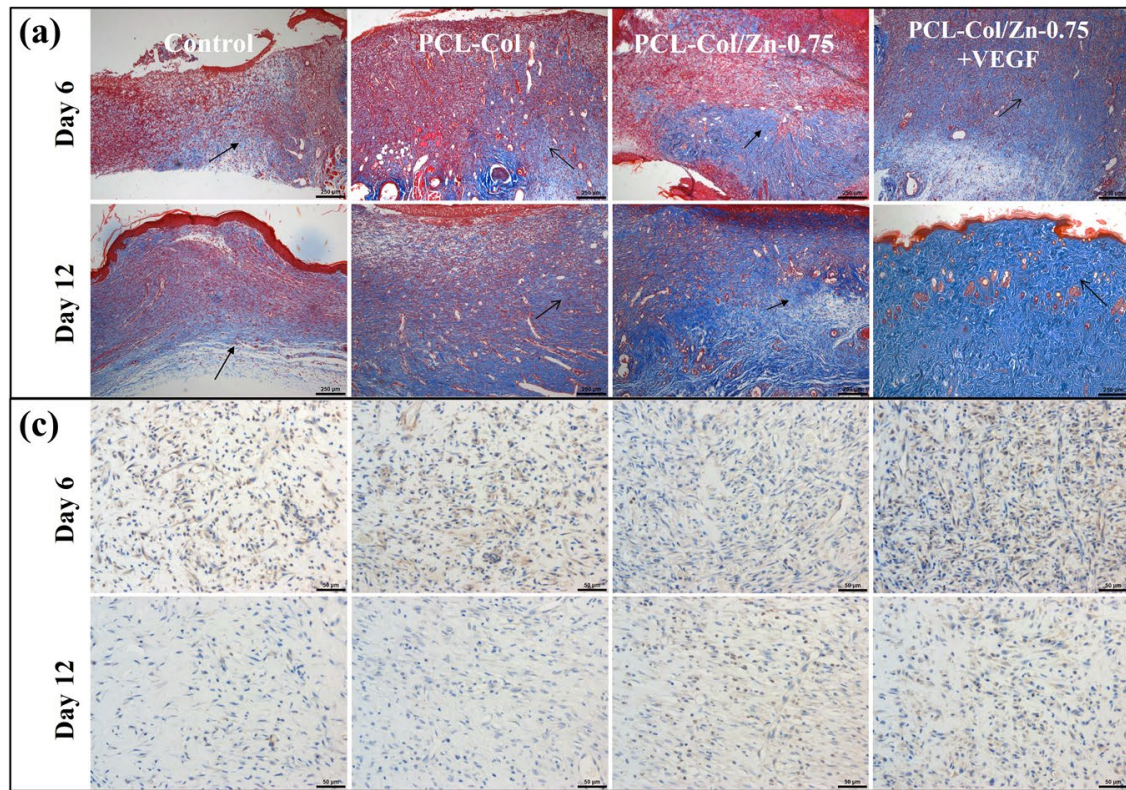

(e)

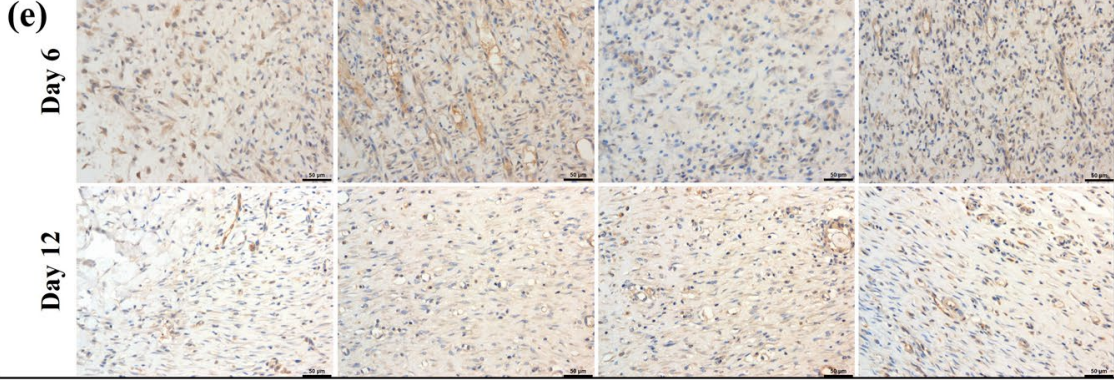

(b)

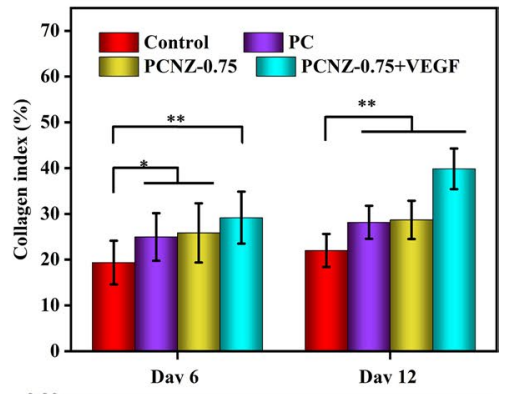

(d)

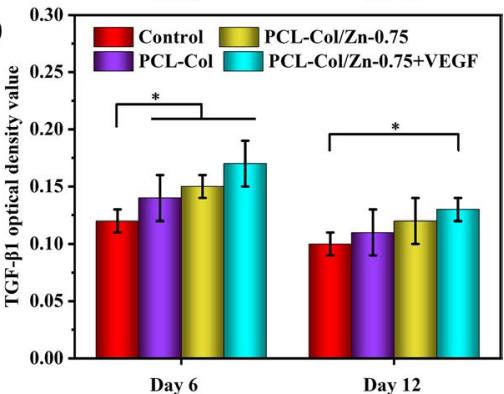

(f)

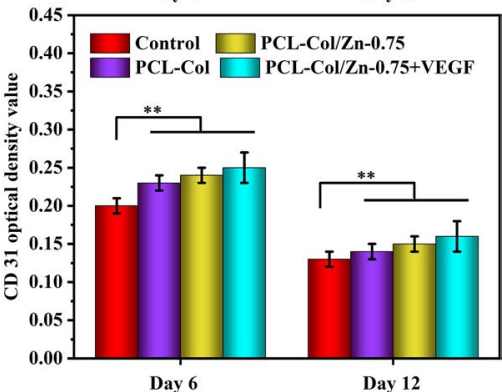

Fig. 9 Masson's trichrome staining images of wound tissue treatment with different fibrous scaffolds (control, PCL-Col, PCL-Col/ZnO0.25 , PCL-Col/ZnO-0.5, and PCL-Col/ZnO-0.75) at days 6 and 12 (a, scale bars: $250 \mu \mathrm{m})$, and column drawing representing its quantitative

\section{Conclusion}

In this work, we have successfully integrated antibacterial $\mathrm{ZnO}$ QDs into the biocompatible PCL/Col fibrous scaffolds by elecspining method to achieve synergistic wound-healing effect. The designed and prepared electrospun PCL-Col/ZnO fibrous scaffolds exhibited well mechanical performance. Also, these fibrous scaffolds performed good swelling and biodegradation behaviors, which were all beneficial for the applications as wound healing. Moreover, the as-fabricated PCL-Col/ZnO fibrous scaffolds showed excellent cytocompatibility and promoting cell proliferation. Besides, the existence of $\mathrm{ZnO}$ QDs endowed the fibrous scaffolds with high-efficient antibacterial properties in vitro against $S$. aureus and E. coli. The resultant electrospun PCL-Col/ ZnO-0.75 + VEGF fibrous scaffolds also exhibited promoted wound-healing effect through promoting expression of TGF- $\beta$ and CD31 in tissues in the early stages of wound healing. This new electrospun fibrous scaffolds with analysis (b). Immunohistochemistry of TGF- $\beta 1$ (c) and CD31 (e) at days 6 and 12 (scale bars: $50 \mu \mathrm{m}$ ), and column drawing of quantitative analysis (d) and (f)

wound-healing promotion and antibacterial property should be convenient for treating wound healing.

Supplementary Information The online version contains supplementary material available at https://doi.org/10.1007/s42235-021-00115-7.

Acknowledgements This work was supported by the Natural Science Foundation of Zhejiang Province (LBY20H110001, LY18E030006) and National Natural Science Foundation of China (51873194).

\section{Declarations}

Conflict of interest The authors declare that they have no conflicts of interest to this work.

\section{References}

1. Byrd, A. L., Belkaid, Y., \& Segre, J. A. (2018). The human skin microbiome. Nature Reviews Microbiology, 16, 143-155.

2. MacNeil, S. (2007). Progress and opportunities for tissue-engineered skin. Nature, 445, 874-880. 
3. Sorg, H., Tilkorn, D. J., Hager, S., Hauser, J., \& Mirastschijski, U. (2017). Skin wound healing: An update on the current knowledge and concepts. European Surgical Research, 58, 81-94.

4. Lanno, G. M., Ramos, C., Preem, L., Putrins, M., Laidmae, I., Tenson, T., \& Kogermann, K. (2020). Antibacterial porous electrospun fibers as skin scaffolds for wound healing applications. ACS Omega, 5, 30011-30022.

5. Jiao, J. H., Peng, C. G., Li, C., Qi, Z. P., Zhan, J., \& Pan, S. (2021). Dual bio-active factors with adhesion function modified electrospun fibrous scaffold for skin wound and infections therapeutics. Scientific Reports, 11, 457.

6. Ghorbani, M., Nezhad-Mokhtari, P., \& Ramazani, S. (2020). Aloe vera-loaded nanofibrous scaffold based on zein/polycaprolactone/ collagen for wound healing. International Journal of Biological Macromolecules, 153, 921-930.

7. Wang, X. C., Lv, F., Li, T., Han, Y. M., Yi, Z. F., Liu, M. Y., Chang, J., \& Wu, C. T. (2017). Electrospun micropatterned nanocomposites incorporated with $\mathrm{Cu}_{2} \mathrm{~S}$ Nanoflowers for skin tumor therapy and wound healing. ACS Nano, 11, 11337-11349.

8. Schoen, B., Avrahami, R., Baruch, L., Efraim, Y., Goldfracht, I., Elul, O., Davidov, T., Gepstein, L., Zussman, E., \& Machluf, M. (2017). Electrospun Extracellular matrix: Paving the way to tailormade natural scaffolds for cardiac tissue regeneration. Advanced Functional Materials, 27, 1700427.

9. Ji, Y., Ghosh, K., Shu, X. Z., Li, B. Q., Sokolov, J. C., Prestwich, G. D., Clark, R. A. F., \& Rafailovicha, M. H. (2006). Electrospun three-dimensional hyaluronic acid nanofibrous scaffolds. Biomaterials, 27, 3782-3792.

10. Dodero, A., Alloisio, M., Castellano, M., \& Vicini, S. (2020). Multilayer Alginate-polycaprolactone electrospun membranes as skin wound patches with drug delivery abilities. ACS Applied Materials \& Interfaces, 12, 31162-31171.

11. Helary, C., Bataille, I., Abed, A., Illoul, C., Anglo, A., Louedec, L., Letourneur, D., Meddahi-Pelle, A., \& Giraud-Guille, M. M. (2010). Concentrated collagen hydrogels as dermal substitutes. Biomaterials, 31, 481-490.

12. Castano, O., Perez-Amodio, S., Navarro-Requena, C., MateosTimoneda, M. A., \& Engel, E. (2018). Instructive microenvironments in skin wound healing: Biomaterials as signal releasing platforms. Advanced Drug Delivery Reviews, 129, 95-117.

13. Rodrigues, M., Kosaric, N., Bonham, C. A., \& Gurtner, G. C. (2018). Wound healing: A cellular perspective. Physiological Reviews, 99, 665-706.

14. Parfejevs, V., Debbache, J., Shakhova, O., Schaefer, S. M., Glausch, M., Wegner, M., Suter, U., Riekstina, U., Werner, S., \& Sommer, L. (2018). Injury-activated glial cells promote wound healing of the adult skin in mice. Nature Communications, 9, 236.

15. Schuhladen, K., Raghu, S. N. V., Liverani, L., Nescakova, Z., \& Boccaccini, A. R. (2021). Production of a novel poly $(\varepsilon-$ caprolactone)-methylcellulose electrospun wound dressing by incorporating bioactive glassand Manuka honey. Journal of Biomedical Materials Research Part B-Applied Biomaterials, 109, 180-192.

16. Sood, A., Granick, M. S., \& Tomaselli, N. L. (2014). Wound dressings and comparative effectiveness data. Advances in Wound Care, 3, 511-529.

17. Rahmati, M., Mills, D. K., Urbanska, A. M., Saeb, M. R., Venugopal, J. R., Ramakrishna, S., \& Mozafari, M. (2020). Electrospinning for tissue engineering applications. Progress in Materials Science, 117, 100721.

18. Agarwal, S., Wendorff, J. H., \& Greiner, A. (2009). Progress in the Field of Electrospinning for tissue engineering applications. Advanced Materials, 21, 3343-3351.

19. Ding, J. X., Zhang, J., Li, J. N., Li, D., Xiao, C. S., Xiao, H. H., Yang, H. H., Zhuang, X. L., \& Chen, X. S. (2019). Electrospun polymer biomaterials. Progress in Polymer Science, 90, 1-34.
20. Rho, K. S., Jeong, L., Lee, G., Seo, B.-M., Park, Y. J., Hong, S.-D., Roh, S., Cho, J. J., Park, W. H., \& Min, B.-M. (2006). Electrospinning of collagen nanofibers: Effects on the behavior of normal human keratinocytes and early-stage wound healing. Biomaterials, 27, 1452-1461.

21. Kubow, K. E., Vukmirovic, R., Zhe, L., Klotzsch, E., Smith, M. L., Gourdon, D., Luna, S., \& Vogel, V. (2015). Mechanical forces regulate the interactions of fibronectin and collagen I in extracellular matrix. Nature Communications, 6, 8026.

22. Abou Neel, E. A., Bozec, L., Knowles, J. C., Syed, O., Mudera, V., Day, R., \& Hyun, J. K. (2013). Collagen-Emerging collagen based therapies hit the patient. Advanced Drug Delivery Reviews, $65,429-456$.

23. Engelhardt, S., Hoch, E., Borchers, K., Meyer, W., Krüger, H., Tovar, G. E. M., \& Gillner, A. (2011). Fabrication of 2D protein microstructures and 3D polymer-protein hybrid microstructures by two-photon polymerization. Biofabrication, 3, 025003.

24. Khosravi, F., Khorasani, S. N., Khalili, S., Neisiany, R. E., Ghomi, E. R., Ejeian, F., Das, O., \& Nasr-Esfahani, M. H. (2020). Development of a highly proliferated bilayer coating on $316 \mathrm{~L}$ stainless steel implants. Polymers, 12, 1022.

25. Dai, N. T., Williamson, M. R., Khammo, N., Adams, E. F., \& Coombes, A. G. A. (2004). Composite cell support membranes based on collagen and polycaprolactone for tissue engineering of skin. Biomaterials, 25, 4263-4271.

26. Guldiken, C. G., Karaosmanoglu, O., Sivas, H., \& Gercel, H. F. (2019). ZnO microparticle-loaded chitosan/poly(vinyl alcohol)/ acacia gum nanosphere-based nanocomposite thin film wound dressings for accelerated wound healing. Journal of Applied Polymer Science, 137, 48445.

27. Homaeigohar, S., \& Boccaccini, A. R. (2020). Antibacterial biohybrid nanofibers for wound dressings. Acta Biomaterialia, 107, $25-49$.

28. Martin, J. R., Nelson, C. E., Gupta, M. K., Yu, F., Sarett, S. M., Hocking, K. M., Pollins, A. C., Nanney, L. B., Davidson, J. M., Guelcher, S. A., \& Duvall, C. L. (2016). Local delivery of PHD2 siRNA from ROS-degradable scaffolds to promote diabetic wound healing. Advanced Healthcare Materials, 5, 2751-2757.

29. Zhu, J. Y., Jiang, G. H., Song, G., Liu, T. Q., Cao, C., Yang, Y. H., Zhang, Y., \& Hong, W. J. (2019). Incorporation of ZnO/bioactive glass nanoparticles into alginate/chitosan composite hydrogels for wound closure. ACS Applied Bio Materials, 2, 5042-5052.

30. Liang, Y., Wang, M. Q., Zhang, Z. C., Ren, G. H., Liu, Y. J., Wu, S. S., \& Shen, J. (2019). Facile synthesis of ZnO QDs@GO-CS hydrogel for synergetic antibacterial applications and enhanced wound healing. Chemical Engineering Journal, 378, 122043.

31. Cai, X. L., Luo, Y. N., Zhang, W. Y., Du, D., \& Lin, Y. H. (2016). $\mathrm{pH}$-sensitive $\mathrm{ZnO}$ quantum dots-doxorubicin nanoparticles for lung cancer targeted drug delivery. ACS Applied Materials \& Interfaces, 8, 22442-22450.

32. Rasmussen, J. W., Martinez, E., Louka, P., \& Wingettt, D. G. (2010). Zinc oxide nanoparticles for selective destruction of tumor cells and potential for drug delivery applications. Expert Opinion on Drug Delivery, 9, 1063-1077.

33. Plonka, P. M., Handjiski, B., Popik, M., Michalczyk, D., \& Paus, R. (2005). Zinc as an ambivalent but potent modulator of murine hair growth in vivo-preliminary observations. Experimental Dermatology, 14, 844-853.

34. Huang, B., Liu, X. M., Li, Z. Y., Zheng, Y. F., Yeung, K. W. K., Cui, Z. D., Liang, Y. Q., Zhu, S. L., \& Wu, S. L. (2021). Rapid bacteria capturing and killing by AgNPs/N-CD@ZnO hybrids strengthened photo-responsive xerogel for rapid healing of bacteria-infected wounds. Chemical Engineering Journal, 414, 128805.

35. Zhang, Y., Chang, M. L., Bao, F., Xing, M., Wang, E. D., Xu, Q., Huan, Z. G., Guo, F., \& Chang, J. (2019). Multifunctional 
Zn doped hollow mesoporous silica/polycaprolactone electrospun membranes with enhanced hair follicle regeneration and antibacterial activity for wound healing. Nanoscale, 11, 6315.

36. Li, H. Y., \& Chang, J. (2013). Stimulation of proangiogenesis by calcium silicate bioactive ceramic. Acta Biomaterialia, 2, 5379-5389.

37. Zhou, Y. L., Gao, L., Peng, J. L., Xing, M., Han, Y., Wang, X. Y., Xu, Y. H., \& Chang, J. (2018). Bioglass Activated albumin hydrogels for wound healing. Advanced Healthcare Materials, 7, 1800144.

38. Yang, J. M., Yang, J. H., Tsou, S. C., Ding, C. H., Hsu, C. C., Yang, K. C., Yang, C. C., Chen, K. S., Chen, S. W., \& Wang, J. S. (2016). Cell proliferation on PVA/sodium alginate and PVA/poly $(\gamma$-glutamic acid) electrospun fiber. Materials Science and Engineering: C, 66, 170-177.

39. Yao, Z. C., Zhang, C. C., Ahmad, Z., Huang, J., Li, J. S., \& Chang, M. W. (2018). Designer fibers from 2D to 3D-simultaneous and controlled engineering of morphology, shape and size. Chemical Engineering Journal, 334, 89-98.

40. Qian, Y. Z., Zhou, X. F., Zhang, F. M., Diekwisch, T. G. H., Luan, X. H., \& Yang, J. X. (2019). Triple PLGA/PCL Scaffold modification including silver impregnation, collagen coating, and electrospinning significantly improve biocompatibility, antimicrobial, and osteogenic properties for orofacial tissue regeneration. ACS Applied Materials \& Interfaces, 11, 37381-27296.

41. Mao, C. Y., Xiang, Y. M., Liu, X. M., Cui, Z. D., Yang, X. J., Li, Z. Y., Zhu, S. L., Zheng, Y. F., Yeung, K. W. K., \& Wu, S. L. (2018). Repeatable photodynamic therapy with triggered signaling pathways of fibroblast cell proliferation and differentiation to promote bacteria-accompanied wound healing. ACS Nano, 2, 1747-1759.

42. Eskandarinia, A., Kefayat, A., Gharakhloo, M., Agheb, M., Khodabakhshi, D., Khorshidi, M., Sheikhmoradi, V., Rafienia, M., \& Salehi, H. (2020). A propolis enriched polyurethane-hyaluronic acid nanofibrous wound dressing with remarkable antibacterial and wound healing activities. International Journal of Biological Macromolecules, 149, 467-476.

43. Zhu, Z., Liu, Y. H., Xue, Y. Y., Cheng, X. T., Zhao, W. F., Wang, J., He, R., Wan, Q. B., \& Pei, X. B. (2019). Tazarotene released from aligned electrospun membrane facilitates cutaneous wound healing by promoting angiogenesis. ACS Applied Materials \& Interfaces, 11,36141-36153.

44. Islam, S., Chuensirikulchai, K., Khummuang, S., Keratibumrungpong, T., Kongtawelert, P., Kasinrerk, W., Hatano, S., Nagamachi, A., Honda, H., \& Watanabe, H. (2020). Accumulation of versican facilitates wound healing: Implication of its initial ADAMTS-cleavage site. Matrix Biology, 87, 77-93.

45. Li, X. H., Shao, C. L., Liu, Y. C., Chu, X. Y., Wang, C. H., \& Zhang, B. X. (2008). Photoluminescence properties of highly dispersed $\mathrm{ZnO}$ quantum dots in polyvinylpyrrolidone nanotubes prepared by a single capillary electrospinning. Journal of Chemical Physics, 129, 114708 .

46. Bellanger, X., Billard, P., Schneider, R., Balan, L., \& Merlin, C. (2015). Stability and toxicity of $\mathrm{ZnO}$ quantum dots: Interplay between nanoparticles and bacteria. Journal of Hazardous Materials, 283, 110-116.

47. Liu, M. C., Sun, X. Y., Liao, Z. H., Li, Y. H., Qi, X. L., Qian, Y. N., Fenniri, H., Zhao, P., \& Shen, J. L. (2019). Zinc oxide end-capped $\mathrm{Fe}_{3} \mathrm{O}_{4} @ \mathrm{mSiO}_{2}$ core-shell nanocarriers as targeted and responsive drug delivery system for chemo-/ions synergistic therapeutics. Drug Delivery, 26, 732-743.

48. Zhou, R., Zhao, Q., Liu, K. K., Lu, Y. J., Dong, L., \& Shan, C. X. (2017). Europium-decorated $\mathrm{ZnO}$ quantum dots as a fluorescent sensor for the detection of an anthrax biomarker. Journal of Materials Chemistry: C, 5, 1685-1691.

49. Zou, T., Xing, X. X., Yang, Y., Wang, Z. Z., Wang, Z. D., Zhao, R. J., Zhang, X., \& Wang, Y. D. (2020). Water-soluble ZnO quantum dots modified by (3-aminopropyl)triethoxysilane: The promising fluorescent probe for the selective detection of $\mathrm{Cu}^{2+}$ ion in drinking water. Journal of Alloys and Compounds, 285, 1504.

50. Ehterami, A., Salehi, M., Farzamfar, S., Vaez, A., Samadian, H., Sahrapeyma, N., Mirzaii, M., Ghorbani, S., \& Goodarzi, A. (2018). In vitro and in vivo study of PCL/COLL wound dressing loaded with insulin-chitosan nanoparticles on cutaneous wound healing in rats model. International Journal of Biological Macromolecule, 117, 601-609.

51. Zhang, Y. Z., Su, B., Venugopal, J., Ramakrishna, S., \& Lim, C. T. (2007). Biomimetic and bioactive nanofibrous scaffolds from electrospun composite nanofibers. International Journal of Nanomedicine, 2, 623-638.

52. Han, J. P., Xiong, L. K., Jiang, X. Y., Yuan, X. Y., Zhao, Y., \& Yang, D. Y. (2019). Bio-functional electrospun nanomaterials: From topology design to biological applications. Progress in Polymer Science, 91, 1-28.

53. Yan, X., Yu, M., Ramakrishna, S., Russell, S. J., \& Long, Y. Z. (2019). Advances in portable electrospinning devices for in situ delivery of personalized wound care. Nanoscale, 11, 19166.

54. Norouzi, M. A., Montazer, M., Harifi, T., \& Karimi, P. (2021). Flower buds like PVA/ZnO composite nanofibers assembly: Antibacterial, in vivo wound healing, cytotoxicity and histological studies. Polymer Testing, 93, 106914.

55. Ahmed, R., Tariq, M., Ali, I., Asghar, R., Khanam, P. N., Augustine, R., \& Hasan, A. (2018). Novel electrospun chitosan/polyvinyl alcohol/zinc oxide nanofibrous mats with antibacterial and antioxidant properties for diabetic wound healing. International Journal of Biological Macromolecules, 120, 385-393.

56. Wan, W. B., Cai, F., Huang, J. Y., Chen, S. X., \& Liao, Q. (2019). A skin-inspired 3D bilayer scaffold enhances granulation tissue formation and anti-infection for diabetic wound healing. Journal of Materials Chemistry B, 7, 2954-2961.

57. Jiang, D. S., \& Scharffetter-Kochanek, K. (2020). Mesenchymal stem cells adaptively respond to environmental cues thereby improving granulation tissue formation and wound healing. Frontiers in Cell and Developmental Biology, 8, 697.

58. Lech, M., \& Anders, H. J. (2013). Macrophages and fibrosis: How resident and infiltrating mononuclear phagocytes orchestrate all phases of tissue injury and repair. Biochimica et Biophysica Acta Molecular Basis of Disease, 7, 989-997.

59. Sapudom, J., Wu, X. C., Chkolnikov, M., Ansorge, M., Anderegg, U., \& Pompe, T. (2017). Fibroblast fate regulation by time dependent TGF- $\beta 1$ and IL-10 stimulation in biomimetic 3D matrices. Biomaterials Science, 5, 1858-1867.

60. Zhu, J. Y., Jiang, G. H., Hong, W. J., Zhang, Y., Xu, B., Song, G., Liu, T. Q., Hong, C., \& Ruan, L. M. (2020). Rapid gelation of oxidized hyaluronic acid and succinyl chitosan for integration with insulin-loaded micelles and epidermal growth factor on diabetic wound healing. Materials Science \& Engineering: C, 117, 111273.

61. Fawcett, J., Buckley, C., Holness, C. L., Bird, I. N., Spragg, J. H., Saunders, J., Harris, A., \& Simmons, D. L. (1995). Mapping the homotypic binding sites in CD31 and the role of CD31 adhesion in the formation of interendothelial cell contacts. Journal of Cell Biology, 128, 1229-1241.

62. Wang, R. F., Zhu, J. Y., Jiang, G. H., Sun, Y. F., Ruan, L. M., Li, P. F., \& Cui, H. Y. (2020). Forward wound closure with regenerated silk fibroin and polylysine-modified chitosan composite bioadhesives as dressings. ACS Applied Bio Materials, 3, 7941-7951.

63. Caligiuri, G. (2019). Mechanotransduction, immunoregulation, and metabolic functions of CD31 in cardiovascular pathophysiology. Cardiovascular Research, 115, 1425-1434.

Publisher's Note Springer Nature remains neutral with regard to jurisdictional claims in published maps and institutional affiliations. 